\title{
Game-changers and transformative social innovation
}

\author{
$\underline{\text { Flor Avelino }}^{1}, \underline{\text { Julia M. Wittmaver }}^{1}$, René Kemp $^{2}$ and Alex Haxeltine $^{3}$
}

\begin{abstract}
This editorial introduces the special feature on the role of game-changers, broadly conceptualized as macro-trends that change the "rules of the game," in processes of transformative social innovation. First, the key concepts are introduced together with the academic workshop that brought together 25 scholars, from across a wide range of disciplines, to discuss the role of game-changers in transformative social innovation, resulting in the 9 contributions in this special feature. Second, the differing conceptualizations of the role of game-changers in transformative social innovation across the set of articles are discussed. Third, an overview is provided of the different empirical examples of game-changers and transformative social innovations addressed; examples were drawn from different geographical contexts across Europe, North America, South America, Africa, and Asia. Fourth, the differing epistemological approaches used to explain social change are noted, and lessons for interdisciplinary and transdisciplinary research on social change discussed. Finally, a synthesis is provided of the main insights and contributions to the literature.
\end{abstract}

Key Words: game changer; sustainability transitions; transformative change; (transformative) social innovation

\section{INTRODUCTION}

A lay term for events and developments that shape the course of history is "game-changer." It is not normally seen as a scientific concept but the issues to which it refers certainly warrant scientific attention. If we accept the notion of game-changer, does it make sense to view certain developments, such as the global economic downturn in 2008 or climate change, as societal game-changers of our times? If so, in what ways do they act as game-changers? Is it through material effects or changed social perceptions about the world? These are the main questions, broadly framed, underlying the articles in this special feature. These questions inspired a two-day academic workshop organized by the Dutch Research Institute for Transitions (DRIFT) at the Erasmus University of Rotterdam at the beginning of September 2014. A total of 25 scholars from across the world gathered to discuss the role of game-changers in transformative social innovation processes, from the perspective of various disciplines, theoretical traditions, and world regions (Avelino et al. 2014a).

Game-changers were broadly conceptualized as macro-trends that are perceived to change the rules of the game, i.e., to change how society is organized and defined by today's understandings, values, institutions, and social relationships (Haxeltine et al. 2013, Avelino et al. 2014b, 2017). The purpose of the game-changer notion was to explore how empirical macro-trends are perceived as game-changing, how they are interpreted, (re)constructed, contested, and dealt with by people working on social innovation and/or social change more generally. The focus of the workshop was on unpacking and discussing, both theoretically and empirically, the global game-changers of our times, e.g., climate change, resource depletion, geopolitical instability, economic crises, increasing inequality, ageing and health, migration, and social cohesion, and to explore how these game-changers relate to different forms of social innovation and transformative change.

This special feature was organized as part of a four-year EU research project, "TRANsformative Social Innovation Theory" (TRANSIT), in which researchers from 12 research institutes collaborated in the study of 20 transnational social innovation networks and 100 local initiatives across 27 countries, with the mission to develop a new theory of transformative social innovation. In this research, social innovation was conceptualized in terms of changing social relations, and transformative social innovation, as a process by which social innovation challenges, alters, or replaces the dominant institutions in the social context (Avelino et al. 2017, Haxeltine et al. 2017).

Contributing authors were invited to introduce societal challenges and game-changers in their specific countries or world regions related to (un)sustainable development; by doing so to reflect theoretically and methodologically on the study of social innovation and/or societal transformation; and to take an interdisciplinary perspective. Below, we shortly introduce each of the articles.

Campos et al. (2016) consider climate change as a game-changer for scientific research and discuss participatory action research as a suitable innovative and reflexive research approach that can link knowledge and action for sustainability. They explore two participatory action research processes in Portugal, a context where participation and deliberative processes are not mainstreamed yet.

The paper by Cipolla et al. (2017) explores the case of Rio de Janeiro in Brazil as a city with "broken" socio-cultural and physical relations, to develop an understanding of both the gamechanging process as changing socio-spatial relations as a whole, and the distinct role of two policy interventions as game-changers therein. In doing so, the paper takes a relational approach and considers urban mobility as a physical and socio-cultural phenomena.

The paper by Gordon et al. (2017) is located in the context of Argentina and Brazil. It focuses on understanding the role of public policies in initiating and supporting social innovation in relation to the game-changers of the long-standing economic and social crisis in the early 2000 s and the rise of populist governments after 2003.

Loorbach et al. (2016) take a transition perspective to explore how the economic crisis is viewed and responded to from a Western-European point of view. Five perspectives are discussed: 
the socioeconomic, the socio-technical, the socio-ecological, the socio-political, and the socio-cultural. The article describes two examples of social innovations with transformative potential (time banking and transition towns) that have experienced increased interest and activity since the economic crisis.

Olsson et al. (2017) argue that current debates on social innovations lack a deeper focus on human-environmental interactions and the related feedbacks, and that such a focus is critical to understanding large-scale transformations to sustainability. The paper explores how the concept of the Anthropocene can inform social innovation theory and practice, and suggests that it creates opportunities for social innovation scholars to creatively imagine new possibilities.

Pel et al. (2016) address the agency of social innovation in "transformation games." The example of the recent threat of electricity blackouts in Belgium is used to illustrate that socially innovative agency cannot just be assumed, and that transformation games may in fact be populated with largely passive players. In some transformation games the crucial gamechanging effect then is to start the game by activating the players.

The paper by Prasad (2016) explores transformative social innovation in Indian agriculture describing the evolution of the System of Rice Intensification (SRI) as social innovation and its relation to game-changing trends such as the (global) agricultural and ecologic crises. It contrasts social innovation with the dominant technocratic innovation paradigm and highlights the importance of a diversity of practices, heterogeneity of networks, and new research paradigms.

Swilling (2016) investigates "game-changing dynamics" in Africa making a distinction between mainstream dynamics such as the commodity boom that started at the millennium and lessrecognized dynamics in the form of social and system innovation responses to water scarcities, land grabbing, soil degradation, slum urbanism, energy poverty, and food insecurity. A case is presented of a project involving the building of shacks equipped with energy and water utilities in an illegal settlement in South Africa.

Finally, the paper by Westley et al. (2016) focuses on historical and cross-scale analysis of how social innovation and gamechangers developed over longer periods of time, in the context of three problem domains in Canada and the USA: wilderness protection, women's rights, and assimilation of indigenous children. Based on this comparative analysis, the authors propose a typology of three types of game-changers: seminal ideas, exogenous shocks, and endogamous opportunities.

\section{CONCEPTUALIZING GAME-CHANGERS IN TRANSFORMATIVE SOCIAL INNOVATION}

Initially, game-changers were broadly conceptualized as "macrophenomena (events and trends) that are perceived to change (the rules, fields and players in the) the 'game' of societal interaction. The dominant understandings, values, institutions and social relationships through which society is organized and defined may fundamentally change in response to game-changing events and trends." (Avelino et al. 2014b:6). Several authors follow this conceptualization of game-changers in their respective articles and subsequently focus on discussing empirical phenomena under study (Campos et al. 2016, Prasad 2016, Cipolla et al. 2017,
Gordon et al. 2017). Others propose alternative concepts to both clarify and broaden our conceptualization of game-changers.

Pel et al. (2016) draw upon insights from actor-centered institutionalism and Actor Network Theory (ANT) to problematize the notion of game-changers. The paper notes that the game-theoretical attention to players' actual interests, prevailing rules, and likely outcomes easily obscures how these may change over time. The authors also take issue with the idea of a fixed playing field. From an ANT perspective agency is fundamentally distributed, and players and field define each other. They call for a more dynamic, multigame perspective in which the structure is not fixed but dependent upon agency, a point that is especially pertinent to transformative social innovators who seek to challenge dominant institutions.

Olsson et al. (2017) argue that conceiving the current geological epoch as the Anthropocene represents a game-changer for social innovation research, calling for a perspective that addresses the linkages between social systems and ecosystems with a time frame for exploring change that is commensurate with the imperative of the Anthropocene.

The multidimensionality of game-changers is also taken up by Loorbach et al. (2016) who address a macro-event (the economic crisis) as being framed from different perspectives: socioeconomic, socio-ecological, socio-technical, socio-political, and socio-cultural. Game-changers are conceptualized as the combination of specific events, the subsequent or parallel framing of events in systemic terms by engaged societal actors, and (eventually) the emergence of (diverse) alternative narratives and practices, in response to the systemic framing of events. Gamechangers do not work separately from social action but through collective action, based on alternative narratives that become aligned with one another through common criticism and shared values.

The paper by Swilling (2016) elaborates a constructivist understanding of game changing dynamics, as something brought about by and invoked through social processes. Game-changing dynamics are defined as complex processes of change that specific actors invoke to justify their particular set of proposed social and system innovations. A distinction is made between "mainstream dynamics" and "less-recognized dynamics," and it is argued that the latter cannot be dealt with through technology or economic policy but require system innovation responses with an important role for social innovation. The author takes issue with the idea of game-changers as external dynamics with inherent agency, something which is said to pertain to the "abstract, almost positivist" notion of exogenous landscape pressures in the sustainability transitions approach (e.g., Grin et al. 2010).

Although several of the abovementioned authors reject exogeneity as an inherent property of game-changers, Westley et al. (2016) position exogenous shocks as one particular type of game-changer. They treat game-changers as "a key aspect of opportunity context (...); shifts in institutions at one scale can allow for new ideas, programs, projects to get traction and secure resources needed for further transformation." Subsequently they empirically explore how different types of game-changers are used by social innovators in their social innovation work, leading to a conceptual typology of three types of game-changers: (1) seminal 
ideas that catalyze social innovation, (2) exogenous shocks that disrupt the continuity of social innovation, and (3) endogamous opportunities that actors themselves use for novel combinations and recombinations.

\section{EMPIRICAL EXAMPLES OF GAME-CHANGERS AND (TRANSFORMATIVE) SOCIAL INNOVATION}

The papers in this special feature expose the multidimensionality of the game-changer notion through the great empirical diversity of how game-changers (and transformative social innovation processes) empirically manifest (see Table 1). Besides the geographical diversity, from Africa, Europe, and India, to Latin America and North America, there is even more variety in terms of problem domains, ranging from specific functional systems, e.g., energy, food, or housing, to broader cross-domain issues such as the science-society interface, urban development, and climate change. Furthermore, there is diversity in temporality, varying from game-changers as single events, e.g., the 2014-2015 Belgian electricity blackout in Pel et al. (2016), to developments spanning a few years, e.g., World War II in Westley et al. (2016) or economic crises in Loorbach et al. (2016) and Gordon et al. (2017), to much slower, long-term developments, such as climate change in Campos et al. (2016) or the Anthropocene in Olsson et al. (2017).

Despite this geographical, functional, and temporal diversity, a clear commonality is that game-changers are placed at relatively high levels of aggregation: all of them being at least at the national scale or higher, the majority being global or international in nature. There are three empirical clusters that seem to be recurring across the papers: (1) (economic) crises, (2) national policy interventions, and (3) the intertwinement of the social and material, both in "socio-technical" and in "socialecological" terms.

\section{(Economic) crises}

The authors discuss a range of crises, mostly economic but also social and ecological. A mixture of all three, can be found in Prasad's (2016) perception of an agricultural crisis as manifested through farmer suicides, productivity increases with stagnating or declining farm incomes, high dependence on external inputs (such as subsidized fertilizers, irrigation based on high extractions of poor quality groundwater), increasing indebtedness, deskilling, drought, and soil deterioration in India. Globally, this agricultural crisis shows through a high and everincreasing ecological footprint, application of synthetic fertilizers as the fastest growing source of greenhouse gas emissions, extractive use of water, and land degrading practices. Westley et al. (2016) discuss the economic depression of the 1930s in the USA and poverty as a subsequent game-changer that helped to promote birth control. Loorbach et al. (2016) discuss the economic recession in the wake of the global financial crisis of 2007-2008, arguing that this phenomena is not just an economic crisis but can also be viewed in terms of an ecological, political, and cultural crisis. Since the beginning of the economic crisis, time banking and transition towns are social innovations with transformative potential that experienced increased interest and activity. Gordon et al. (2017) discuss as a game-changer "the peak of a long-standing economic and social crisis that was the result of years of neoliberal policies" that Argentina and Brazil faced in the early 2000s, which resulted in social exclusion, reduction of government capabilities, and social turmoil.

\section{(National) policy interventions}

Policy interventions feature in a number of papers and are emphasized in the Latin American cases, as either game-changing enablers for social innovation or as social innovations in themselves. Cipolla et al. (2017) focus on Rio de Janeiro in Brazil as a "broken city," a city with broken socio-cultural and physical relations. They frame transformative social innovation as a process in which these socio-spatial relations are drastically changed, and in which the "broken city" undergoes reconnections. Two specific policy measures, one aimed at installing community policing in favelas (Pacifying Police Unit) and one aimed at the provision of free Internet access for favela residents (State of Rio Digital) are considered as game changing interventions allowing new courses of play. Gordon et al. (2017) discuss three cases to demonstrate different ways in which public policies played a role in facilitating, supporting, and at times co-opting social innovation in Argentina and Brazil: (1) a large-scale rural and semiurban family farming program (Pro-Huerta program), (2) a water supply program (P1MC, The One Million Cisterns Program) aimed at building a massive number of water cisterns in a large semiarid region in north eastern Brazil, and (3) the National Technology and Social Innovation Program that was created by the Argentinian Ministry of Science, Technology and Innovation to foster the creation, use, and diffusion technology for social inclusion projects.

\section{The intertwinement of the social and material}

A third cluster of recurring empirical themes in the discussion of game-changers is that of the socio-material intertwinement of transformative social innovation with socio-technical and socialecological developments. Pel et al. (2016) substantiate their proposed understanding of "Transformative Social Innovation games" through an illustrative case of the 2014-2015 Belgian electricity blackout threat. Because this challenge to the electricity provision game seemed unsolvable through regular grid management strategies, alternative ideas about the field gained traction. Socio-technical and social-ecological intertwinements are brought out in the discussion by Swilling (2016) of five actor networks that are active in creating a renewables-based electricity system, fighting land grabbing and soil degradation, overcoming food insecurity and water scarcities, and finally in providing better housing with infrastructure facilities in illegals slums. Prasad (2016) considers the agricultural and ecological crises to open up spaces for social (-technical) innovations such as the System of Rice Intensification to emerge. The latter offers an alternative, more social, narrative of change that goes against the current technocratic innovation paradigm in Indian agriculture. This social-ecological dimension is further elaborated by Olsson et al. (2017) who argue that the Anthropocene demands that any innovation has both a social and ecological element, that is, one cannot have a social innovation without an ecological impact, nor an ecologically based innovation without considering the social impact. The ramifications of an Anthropocene perspective are discussed for three case examples: the Maine lobster fishery system, the Baltic Sea Action Group, and India's Barefoot College. Campos et al. (2016) focus on the specific socialecological development of climate change, which they consider as a game-changer for the science system. 
Table 1. Empirical examples of game-changers and transformative social innovation across contributions.

\begin{tabular}{|c|c|}
\hline Article & Empirical examples of game-changers \\
\hline $\begin{array}{l}\text { Campos et } \\
\text { al. } 2016\end{array}$ & Climate change as game-changer for the scientific system. \\
\hline $\begin{array}{l}\text { Cipolla et } \\
\text { al. } 2017\end{array}$ & $\begin{array}{l}\text { Two policy measures: } \\
\text {-Installing community policing in favelas (Pacifying Police Unit); } \\
\text {-Provision of free Internet access for favela residents (State of Rio } \\
\text { Digital). }\end{array}$ \\
\hline $\begin{array}{l}\text { Gordon et } \\
\text { al. } 2017\end{array}$ & $\begin{array}{l}\text {-Economic and social crisis in early } 2000 \text { s (following neoliberal period } \\
\text { of } 1990 \text { s). } \\
\text { - Rise of populist governments after } 2003 \text {. }\end{array}$ \\
\hline $\begin{array}{l}\text { Loorbach } \\
\text { et al. } 2016\end{array}$ & $\begin{array}{l}\text { Economic recession in the wake of the global financial crisis of } 2007- \\
2008 \text {, being perceived in terms of: } \\
\text {-socioeconomic: poverty, exclusion, poor skills, (youth) unemployment, } \\
\text { job uncertainty, and precarious work; } \\
\text { •social-ecological: ecological degradation and ecological debt due to } \\
\text { unlimited economic growth } \\
\text {-socio-technical: information and communications technology } \\
\text { revolution resulting in internet bubble with financial innovations, } \\
\text { speculations, and overinvestments; } \\
\text {-socio-political: erosion of trust in established institutions and } \\
\text { increasing societal critique of wealth accumulations by powerful } \\
\text { political and financial elites; } \\
\text {-socio-cultural: individualistic and materialistic worldviews resulting in } \\
\text { alienation and loss of identity. }\end{array}$ \\
\hline
\end{tabular}

Empirical examples of (transformative) social innovations
Participatory action research as a socially innovative research
practice that has potential to support a sustainability transition
in the context of climate adaptation.

Geographical

Context

in the context of climate adaptation.

Social network providing alerts about violence in a specific

Portugal

favela;

- Collective for cultural production by normal residents;

-Literary festival in the favelas aimed at boundary-crossing dialogue.

Brazil

The Anthropocene as a game-changer for social innovation practice.

Pel et al. Electricity blackout threat in Belgium 2014-2015.

2016

Three social innovations in:

-large-scale rural and semiurban family farming;

-water supply;

-technology for social inclusion projects.

-Time Banks, a reciprocal service exchange system using time as the unit of exchange and account.

-Transition Towns, as an organizational vehicle for citizen-based initiatives to practice alternative economic and social activities.

South America:

Argentina and Brazil

Europe

- Maine lobster fishery system (that has sustained and regulated economically valuable lobster fisheries).

- Baltic Sea Action Group (that addressed the problem of a very polluted and eutrophic Baltic Sea).

-India's Barefoot College (that deeply challenged the conventions of village life, professional associations, and traditional culture).

Warning sent to all institutional and societal players (households, enterprises, industries, and administrations) asking them to reduce their electricity consumption during key hours of shortage. The diverse actors involved responded in widely varying ways to this call.

-System of Rice Intensification as a social (-technical) innovation that provides a new narrative of change against the current Green Revolution-practices in Indian agriculture.

-Agricultural and ecological crisis: manifesting in farmer suicides,

Prasad productivity increases with stagnating or declining farm incomes, hig dependence on external inputs (e.g., subsidized fertilizers, irrigation based on high extractions of poor quality groundwater), increasing indebtedness, deskilling, drought, and soil deterioration. - Global agricultural crisis: ever-increasing ecological footprint, application of synthetic fertilizers as fastest growing source of greenhouse gas emissions, extractive use of water and land degrading practices.

Swilling $\quad$ Recognized game-changers: commodity prices boom creating wealth, 2016 economic volatility, the creation of a better educated middle class with purchasing power, a rebirth of manufacturing, and the use of policies for macro-economic stabilization change the landscape of Africa. -Less-recognized game-changers: need for a renewables-based electricity system, land grabbing and soil degradation, slum urbanism, food insecurity, and water scarcities.

-Slack/Slum Dwellers International (SDI; Community-based savings and loans groups);

-The Africa Clean Energy Corridor initiative;

-The African Food Security Network, the Africa Organic Network.

-iShack project: researchers working with community people and municipal officers to create shacks with electricity and water collecting systems in an illegal slum settlement in South Africa.

Westley et Development of national parks as social innovation:

al. 2016 -Seminal ideas: Romanticism, romantic environmentalism (end of the 18th century);

-Exogenous shocks: World Wars;

-Endogamous: Colonist tendencies to extract wealth from new lands, attempts to recover nature, conservation science inventorization of new species of flora and fauna.

Legalization of Contraception as social innovation:

-Seminal ideas: birth control movement (beg. 20th century);

-Exogenous shocks: World War I;

-Endogamous: technological and medical advances, commercialization of abortions, domestic manufacturing of condoms, venereal disease scare in WWI, poverty and depression in the 1930s, private sector's desire to supply for market demand, a Supreme Court decision legalizing contraceptive devices.

Residential school system as social innovation:

-Seminal ideas: colonialist ideologies and disregard for other cultures;

-Exogenous shocks: World War II;

-Endogamous: colonial assimilation combined with indigenous philosophy on indigenous children receiving white education.
Global

Belgium

India

Africa

USA \&

Canada 


\section{INTERDISCIPLINARY AND TRANSDISCIPLINARY PERSPECTIVES ON GAME-CHANGERS AND TRANSFORMATIVE SOCIAL INNOVATION}

Most of the papers demonstrate an interdisciplinary approach: they acknowledge (different perspectives on) the interaction between culture, politics, technology, ecology, and economy to understand game-changers and processes of transformative change. Moreover, there is a shared sense of "interparadigmatic" research: to understand the role of, e.g., planetary boundaries or climate change in transformative social innovation, it is necessary to acknowledge both their biophysical reality as well as their social constructions (Hulme 2009). These social constructions are not less real, for they become social facts that are acted on (Westley et al. 2016 in ref. to Durkheim).

Loorbach et al. (2016) build on transition research as an interdisciplinary perspective on societal change and take perspectives from different disciplines (economic, ecological, technological, political, and cultural) to unpack the economic crisis. The paper by Cipolla et al. (2017) considers urban mobility as spanning both physical as well as social-cultural aspects. Its argumentation is therefore by default interdisciplinary drawing upon the "mobilities turn" in social sciences (Urry 2007) and writings on territorial development through social innovation (Moulaert 2009). Olsson et al. (2017) bring together scholarship on social innovation with a social-ecological systems framing. Westley et al. (2016) draw on complexity theory, resilience theory, and structuration theory, all of which are explicitly interdisciplinary perspectives. Methodologically their paper is focused on a historical analysis of how social innovations develop over longer periods of time in interaction with their opportunity contexts.

Besides research on transformative social change, some papers also address the issue of research for transformative social change, i.e., how research can engage with societal challenges through becoming actively involved. Transdisciplinary research and participatory action research are discussed as ways to move beyond a closed academic realm, to involve the experience and tacit knowledge of practitioners. Although the papers and respective research approaches differ in their transformative and activist ambitions, a commonality lies in reflexivity and (a call for) awareness regarding the normative orientations of transformative social innovation cases. Swilling (2016) makes a plea for a transdisciplinary research approach, where researchers are embedded in the social processes they are studying to generate transformation knowledge. Transdisciplinary research includes the coformulation of problems by researchers and community and generates knowledge for useful action. Transformation knowledge is necessary for translating collective problem identification into localized social innovations that can stimulate system innovation at nonlocal scales. Campos et al. (2016) emphasize the importance of participatory action research (PAR) with societal actors for addressing game changing developments. By conceptualizing climate change as a game-changer for the scientific system, the paper highlights the coproduction of science and society, pointing to the fact that new societal challenges call for new methodological approaches. With two rich empirical cases of PAR as a socially innovative research approach in the Portuguese science system, this paper accomplishes both: to show the merits as well as the pitfalls of such research and thereby a more realistic idea of what it can accomplish in the face of current societal challenges.

Part of the analysis and critique of the paper by Prasad (2016) is the role of science and the science system: it argues for both interand transdisciplinarity for strengthening sustainability transitions. Prasad considers that next to "active dissent by CSOs and farmer groups," what is required are "creative dissenters within the scientific establishment who have the ability to listen to nonresearch actors and translate ideas of paradigm change and sustainability to agricultural researchers." Networks have provided space for conversations across the boundaries of their own disciplines. He bases these ideas on Gandhi's experiments with a "science by people" as a precursor of "social innovation."

\section{CONCLUSION AND SYNTHESIS}

Conclusions and insights from the papers in this special feature can be clustered around four contributions to scholarship on social innovation and transformative social change.

\section{Game-changers as a metaphor}

The diversity in the use of the metaphor of game-changer is reflected across the nine papers, which provide a rich variety of typologies, characterizations, and empirical illustrations of gamechangers. Weather storms, socio-technical movements, the economic crisis, the Anthropocene and World Wars, but also narratives, conflict, policy interventions, or social innovations, can all be discussed as game-changers. The papers propose several typologies and distinctions between different types of gamechangers, including mainstream versus less-recognized, seminal, exogenous or endogamous, single events versus long-term developments. One conclusion is that game-changers should not be equated with macro-developments., i.e., not be confined to any specific level (macro, meso, or micro). If the game consists of rules, fields, and players, all these elements can act as gamechangers in their own right. The strength of the game-changer notions lies in the exploration of the interplay of different empirical phenomena over time at different scales and the ensuing interpretative and comparative discussion on the extent to which these phenomena influence each other by both enabling and impeding change.

The papers in this special feature also invite us to remain critical of the game metaphor. On the one hand, the diversity of the gamechangers metaphor, as displayed in the different conceptual and empirical examples across the papers, is one of its strengths in inviting diverse and creative approaches to look at diverse empirical phenomena from different perspectives. On the other hand, it is also a weakness in that this blurriness does not allow for clear conceptual definitions and indicators. Moreover, as this game metaphor emphasizes, the need for changing the rules, i.e., structural transformative change, one could argue that it invokes a way of thinking, e.g., in terms of winners and losers, beginning and end, and competition, that could reproduce those very structures that some transformative social innovation endeavors aim to challenge. Although there is no need to discard the metaphor of game-changers altogether, there is a need to remain aware of the contributions and limitations of such metaphors and associated narratives. 


\section{Structural opportunity contexts for agency}

A recurring issue across the papers is how the structural context, and the developments therein, acts as an opportunity context for human agency. The papers demonstrate a rich variety of perspectives on the structural context. For some, the structural context is, by definition, the object of transformative social innovation, in the sense that the transformative aspect of social innovation is defined by the extent to which the structural context is altered, be it change in regimes, institutions, or rules. For others, the context is part of the agency of transformative social innovation in that it is framed by those engaged. Social innovation, actors, and structures codevelop and can all be understood as constantly being negotiated and reshaped.

Loorbach et al. (2016) argue that "social innovators can increase the transformative potential of their social innovations by smartly playing into the societal game changers of their times, while simultaneously connecting to political (calls for) system innovation, as well as linking up with multilayered narratives of change in both mainstream and grassroots movements." Pel et al. (2016) draw upon insights from actor-centered institutionalism and ANT to problematize the notion of game-changers and develop a framing of the agency of social innovation in transformation games. In this framing: the players are not simplistically understood as moving through a solid field: rather players and field define each other, and agency is distributed. Social-ecological relations and interactions with nonhuman players are key and it is understood that the interests of players may change over time; participants may be active players of the game, or they may be passive and remain to be activated. They thus discuss the Janus face of the context, as an enabler for certain actions and constrainer of change, especially transformative change.

The human goals and ambitions in transformative social innovation processes will differ and result in ideological projects, which in hindsight will be judged as evil or good by different people. Westley et al. (2016) argue that each successful social innovation "becomes a powerful adjacent possible, an endogamous game changer for other social innovations." The empirical examples demonstrate that social innovation does not assume automatic positive outcomes, and may in fact be judged negatively by history (as was the case with residential schools in Canada). As such, the authors conclude that social innovation "requires constant reassessment and ethical vigilance: as social innovators increase their effectiveness, so they must also be alert to the almost inevitable negative consequences of social innovation." There may also be a bright side to seemingly "dark" phenomena, as dissent, violence, crisis, and conflict may at times be experienced as drivers for transformative agency.

\section{Perspectives from the Global South}

One of the main contributions of the special feature are the perspectives from the Global South on transformative social innovation, ranging from India and Africa to Latin America. Prasad (2016) explicitly situates the current movement for the System for Rice Intensification in the historical and cultural experiences with social innovations in India, thereby legitimizing it as a culturally suited narrative of change in opposition to the Green Revolution practices. Prasad also points to the importance of learning alliances and networking as strategies for social innovators to succeed in the Indian context where formal and official institutions have a different status.

The paper by Gordon et al. (2017) emphasizes the dialectic relationship between public policies and social innovation. Although the economic and financial crisis of the early 2000s triggered "a wave of social innovation" experiments and movements in Argentina and Brazil, the authors argue that it was primarily the subsequent rise of a populist government that strengthened public policies, which in turn were pivotal in inciting, supporting, and sheltering social innovation initiatives in the South American context. Similarly, Cipolla et al. (2017) analyzes the interaction of public measures as game changers with social innovation initiatives. They flag the importance of metaphorical frames, especially the frame of a broken city. An important conclusion from this study is that the reconnection of the broken city is a process of social-spatial transformation that is coproduced by symbiotic but also divergent forces.

Africa faces challenges of structural transformation of a different kind: the need for electrification, food security, and slum-based forms of urbanization. According to Swilling (2016), the commodity boom is the mega-game-changing dynamic driving the overarching need for structural transformation, which will require more than modernization through industrialization. Swilling notes the importance of science in generating transformative knowledge through transdisciplinary research projects.

\section{Socio-material and translocal intertwinement}

Social innovations and game changing events and developments are intertwined with socio-material elements across socio-spatial scales. All papers demonstrate, implicitly or explicitly, multiscale connections, namely how global, international, and national developments and events are intertwined with local projects and activities. For example the connections between the threat of a national electricity blackout with a wide variety of actions from different actors at very local scales (Pel et al. 2016), or between the economic crises and such local activities as time sharing and urban gardening (Loorbach et al. 2016).

In this regard, the papers bring out two criticisms to social innovation research. The first criticism is that socio-spatial relations have important material dimensions that are often neglected in social innovation research (see also Van Dyck and van den Broek 2013). The second criticism is that the current debate on social innovation for sustainability lacks a deeper focus on human-environmental interactions and feedbacks that is necessary to understand transformations to sustainability (Olsson et al. 2017).

As for the ecology-society relationship, Olsson et al. (2017) argue that social innovation can be of use in navigating toward fundamentally changed people-planet relationships. To do so social innovation research must move toward confronting the need for "bricolage" that includes social and ecological elements to address the integrated and systemic nature of the Anthropocene. The authors are critical of a humans-first approach but contend that the magnitude and number of ecological challenges calls for social innovations that contribute to transformative change. In their own words, we should "move away from generating innovations that, at best, reduce negative 
impacts, and at worst, create long-term problems in other areas, toward approaches that help humanity become a positive force on the planet and create a good Anthropocene."

Responses to this article can be read online at: http://www.ecologyandsociety.org/issues/responses. $\mathrm{php} / 9897$

\section{Acknowledgments:}

The authors would like to thank all the participants of the 2014 workshop in Rotterdam as well as the contributors to this special feature for the fruitful collaboration. This article is based on research carried out as part of the Transformative Social Innovation Theory (TRANSIT) project, funded by the European Union's Seventh Framework Programme (FP7) under grant agreement 613169. The views expressed in this article are the sole responsibility of the authors and do not necessarily reflect the views of the European Union.

\section{LITERATURE CITED}

Avelino, F., J. Wittmayer, A. Haxeltine, R. Kemp, T. O'Riordan, P. Weaver, D. Loorbach, and J. Rotmans. 2014b. Game-changers and transformative social innovation. The case of the economic crisis and the new economy. TRANSIT working paper. DRIFT, Rotterdam, Netherlands. [online] URL: http://www.

transitsocialinnovation.eu/content/original/TRANSIT $\% 20$ outputs/91\% 20Gamechangers_TSI_Avelino_etal_TRANSIT_workingpaper_2014. pdf

Avelino, F., J. Wittmayer, and B. Kirner. 2014a. Report synthesis workshop game-changer \& transformative social innovation. TRANSIT Proceedings, Synthesis Workshop, Rotterdam, 01-02 September. TRANSIT: EU SSH.2013.3.2-1 Grant agreement no: 613169 .

Avelino, F., J. M. Wittmayer, B. Pel, P. Weaver, A. Dumitru, A. Haxeltine, R. Kemp, M. S. Jørgensen, T. Bauler, S. Ruijsink, and T. O'Riordan. 2017. Transformative social innovation and (dis) empowerment. Technological Forecasting and Social Change. http://dx.doi.org/10.1016/j.techfore.2017.05.002

Campos, I., F. M. Alves, J. Dinis, M. Truninger, A. Vizinho, and G. Penha-Lopes. 2016. Climate adaptation, transitions, and socially innovative action-research approaches. Ecology and Society 21(1):13. http://dx.doi.org/10.5751/ES-08059-210113

Cipolla, C., R. Afonso, B. Pel, R. Bartholo, É. R. Silva, and D. Proença Júnior. 2017. Coproduced game-changing in transformative social innovation: reconnecting the "broken city" of Rio de Janeiro. Ecology and Society 22(3):3. http://dx.doi. org/10.5751/ES-09362-220303

Gordon, A., L. D. Becerra, and M. Fressoli. 2017. Potentialities and constraints in the relation between social innovation and public policies: some lessons from South America. Ecology and Society 22(4):2. http://dx.doi.org/10.5751/ES-09493-220402

Grin, J., J. Rotmans, and J. Schot. 2010. Transitions to sustainable development: new directions in the study of long term transformative change. Routledge, New York, New York, USA
Haxeltine, A., F. Avelino, J. Wittmayer, R. Kemp, P. Weaver, J. Backhaus, and T. O'Riordan. 2013. Transformative social innovations: a sustainability transition perspective on social innovation. Paper presented at NESTA Social Innovation Research Conference, November 14-15. 2013. London, UK. [online] URL: http://www.scribd.com/doc/191799102/Transformativesocial-innovations-A-sustainability-transition-perspective-on-socialinnovation

Haxeltine, A., B. Pel, A. Dumitru, R. Kemp, F. Avelino, M. Søgaard Jørgensen, J. Wittmayer, I. Kunze, J. Dorland, and T. Bauler. 2017. TRANSIT WP3 Deliverable D3.4 - consolidated version of TSI theory. TRANSIT: EU SSH.2013.3.2-1 grant agreement n. 613169.

Hulme, M. 2009. Why we disagree about climate change: understanding controversy, inaction and opportunity. Cambridge University Press, Cambridge, UK. http://dx.doi.org/10.1017/ CBO9780511841200

Loorbach, D., F. Avelino, A. Haxeltine, J. M. Wittmayer, T. O'Riordan, P. Weaver, and R. Kemp. 2016. The economic crisis as a game changer? Exploring the role of social construction in sustainability transitions. Ecology and Society 21(4):15. http://dx. doi.org/10.5751/ES-08761-210415

Moulaert, F. 2009. Social innovation: institutionally embedded, territorially (re)produced. Pages 11-23 in D. MacCallum, F. Moulaert, J. Hillier, and V. Haddock, editors. Social innovation and territorial development. Routledge, London, UK.

Olsson, P., M.-L. Moore, F. Westley, and D. McCarthy. 2017. The concept of the Anthropocene as a game-changer: a new context for social innovation and transformations to sustainability. Ecology and Society 22(2):31. http://dx.doi.org/10.5751/ ES-09310-220231

Pel, B., G. Wallenborn, and T. Bauler. 2016. Emergent transformation games: exploring social innovation agency and activation through the case of the Belgian electricity blackout threat. Ecology and Society 21(2):17. http://dx.doi.org/10.5751/ ES-08346-210217

Prasad, S. 2016. Innovating at the margins: the system of rice intensification in India and transformative social innovation. Ecology and Society 21(4):7. http://dx.doi.org/10.5751/ES-08718-210407

Swilling, M. 2016. Africa's game changers and the catalysts of social and system innovation. Ecology and Society 21(1):37. http:// dx.doi.org/10.5751/ES-08226-210137

Urry, J. 2007. Mobilities. Polity Press, Cambridge, UK.

Van Dyck, B. and P. Van den Broeck. 2013. Social innovation: a territorial process. Pages 131-141 in F. Moulaert, D. MacCallum, A. Mehmood, and A. Hamdouch, editors. The international handbook on social innovation: collective action, social learning and transdisciplinary research. Edward Elgar, Cheltenham, UK. http://dx.doi.org/10.4337/9781849809993.00021

Westley, F. R., K. A. McGowan, N. Antadze, J. Blacklock, and O. Tjornbo. 2016. How game changers catalyzed, disrupted, and incentivized social innovation: three historical cases of nature conservation, assimilation, and women's rights. Ecology and Society 21(4):13. http://dx.doi.org/10.5751/ES-08811-210413 